See discussions, stats, and author profiles for this publication at: https://www.researchgate.net/publication/318474148

\title{
The effect of Rio Convention and other structural breaks on long-run economic development-CO2 relationships
}

Article in Economia Politica · July 2017

DOI: $10.1007 / 540888-017-0069-z$

CITATIONS

2

2 authors:

Massimiliano Mazzanti

University of Ferrara

197 PUBLICATIONS 4,753 CITATIONS

SEE PROFILE
READS

47

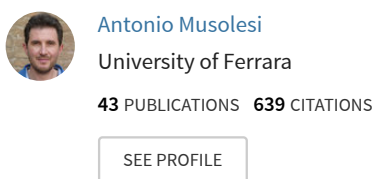

Some of the authors of this publication are also working on these related projects:

The European Topic Centre on waste and materials in a green economy View project

EEA SEEDS webinar September 30 - Sustainability transitions in an age of demographic and technological change View project 


\title{
The effect of Rio Convention and other structural breaks on long-run economic development-CO2 relationships
}

\author{
June 14, 2017
}

\begin{abstract}
This paper assesses the effect of the 1992 United Nations Rio Convention on Environment and Development and other unknown structural time breaks on the long-run carbon dioxideeconomic development relationship for different groups of advanced countries. By taking into account the possible size distortion of standard unit roots tests and allowing nonlinearities in the trend function, we provide evidence suggesting that the time-series are nonlinear trend stationary. From this result, we then develop our analysis without moving to cointegration or first-differencing, and using an interrupted time-series approach, we identify three patterns in the dynamics of carbon dioxide: one is market-led, one is market- and policy-led, and one is more development-oriented.
\end{abstract}

JEL classification: C22; Q53.

Keywords: Carbon Kuznets curves, UN Rio convention, policy events, oil shocks, intervention analysis, structural breaks

The manuscript is available as a working paper on "Econpapers- RePEc organization" https://ideas.repec.org/p/srt/wpaper/1815.html

\section{Introduction}

The relationship between climate change and economic development (Grossman and Krueger 1995, Carson, 2010) has received a great deal of attention since the establishment of climate change policy meetings such as the Rio 1992 Convention, which paved the way for the Kyoto summit in 1997. Since then, the world economy has witnessed the economic upturn of most emerging economies, which has brought about massive increases in greenhouse gas (GHG) emissions. Most developed countries have often played leadership roles in GHG abatement strategies, with Northern European 
countries standing first in this ranking (Mazzanti and Musolesi, 2013). On this basis, the EU launched a new binding target for 2030 in January 2014 to cut emissions by about $40 \%$ with respect to 1990 levels (the EU Kyoto target was a cut of 8\%). In 2015, the United Nations Climate Change Conference (COP21), was organized in Paris. Though a success to some extent - namely, the recognition of the necessity of stabilizing temperatures below a defined threshold - the conference did not generate a setting for a globally coordinated environmental policy agenda. Financially speaking, countries should contribute to the funding of a Global Carbon Fund, eventually through ecological tax revenues (Ekins and Speck, 2011; EEA, 2016). As far as strict environmental policy implementation is concerned, countries are free to choose their most desirable implementations at national and regional levels, without having to pursue specific targets (as in the Kyoto era). There thus remains a strong necessity to learn from the past to develop future targets and international agreements, even more so within a setting where the actions of individual countries/regions, rather than 'global protocols', play a primary role.

Mazzanti and Musolesi (2014) recently analyzed various groups of advanced countries within the OECD area. In particular, they focused on the 'Umbrella group' (Barrett, 2003 for a definition of the group, which is essentially formed of countries that have historically placed mild/low policy emphasis on climate change) comprising North America, Japan, and Oceania; Northern Europe $(\mathrm{NE})$; and Southern Europe (SE) and concluded that nonlinear time effects weigh more than income in driving carbon emissions. These time-related factors explain the reduction of $\mathrm{CO}_{2}$ levels in Northern Europe, where a bell-shaped carbon-income relationship is observed only for the Scandinavian countries. This evidence highlights the fallacy of simplistic environmental Kuznets curve (EKC) interpretations (Harbaugh et al., 2002; Brock and Taylor, 2010) and necessitates further investigations of specific time-related events. Indeed, separating income and time effects by using a smoothing nonparametric approach is useful for capturing complex nonlinear dynamics; however, the specific time events that had (eventually abrupt) effects on emissions trends remain unexplored.

The paper touches on a new strand of literature, which analyzes the long-run relationship between the economy and the environment (here, economic development $-\mathrm{CO}_{2}$ ) and assesses the possible variables' stationarity around a deterministic nonlinear trend (Bierens, 1997) - which generalizes the idea that a time series can be stationary around a breaking deterministic linear trend, as in Zivot and Andrews (1992) and Perron (1989) - while most of the previous studies assume that the variables are first-order integrated processes (e.g., Perman and Stern, 2003). Then, by using an interrupted time series approach (Box and Tiao, 1975; Pankratz, 1991), this paper investigates the impact of temporal structural breaks on the above-mentioned groups of advanced countries. Currently, these countries play a leadership role in GHG reduction proposals, although with heterogeneous targets and policy approaches. Reactions to historical shocks, such as major policy events, oil price shocks and (correlated) wars (Hamilton, 2003), may strongly differ between such groups and, in turn, may heterogeneously affect emissions (Almer and Winkler, 2017; Hamilton, 2003). Panopoulou and Pantelidis (2009) show that the oil crisis affected carbon 
'club' convergence in per capita carbon emissions. Their study on clubs and structural similarity over time shows that while convergence at the global level, among all countries, was significant in 1960-1985, it was not significant in 1975-2003.

The present paper primarily focuses on a key historical well-known policy event, i.e., the 1992 UN Framework Convention on Environment and Development that was held in Rio (henceforth denoted as 92RC in comments and tables), and also consider other unknown time breaks that might have shaped the possibly nonlinear long-run carbon-development relationship. In principle, there is almost an infinity of ways to model structural breaks. They may differ with respect to their duration (transitory or permanent), their onset (gradual or abrupt) and may take many alternative shapes. We detect the time and the pattern of these breaks using the the methods described by de Jong and Penzer (1998). This allows the detection of different types of breaks, which are modeled, for example, by combining a step or a pulse function with alternative transfer functions (see, e.g., Box and Tiao, 1975; Perron, 2006).

\section{Data and preliminary unit root tests}

\subsection{Data}

We use the same data and group definitions used by Mazzanti and Musolesi (2013, 2014), who analyzed carbon dioxide-income relationships in a panel data setting. We refer to these studies for a more detailed presentation of the data and samples. The countries are categorized according to specific structural features related to climate change issues. We consider three groups: the 'Umbrella group' formed by North America, Japan and Oceania; Northern Europe (NE); and Southern Europe (SE). The sample covers the period 1960-2001. For the specific purpose of this paper, that is, studying the aggregate behavior of the above-defined areas, the countries are aggregated, which results in time series variables - per capita $\mathrm{CO}_{2}$ emissions and per capita GDP - for each group of countries.

\subsection{Preliminary unit root tests}

Before estimating the model, a preliminary statistical analysis is conducted to detect the order of integration of the variables. This has relevant implications for model building. We first perform the Augmented Dickey-Fuller (ADF) test as a benchmark, including a linear time trend in the auxiliary regression and setting the lag order $(p)$ by using the AIC starting from an AR(5) model. The ADF tests provide evidence that favors the unit root hypothesis for all of the time series ${ }^{1}$. However, because unit roots tests applied to time series of moderate sample sizes may suffer from size distortion, we simulate the p-value for the ADF test using an AR(p) Gaussian model and

\footnotetext{
${ }^{1}$ Carson (2010) comments on the relative paucity of time series analysis within the EKC literature since its inception, while discussing causality issues and econometric models.
} 
use the wild bootstrap (Hardle and Mammen, 1991) based on 2000 replications. Moreover, based on Kwiatkowski et al. (1992), who argue that the standard unit root tests are not very powerful against relevant alternatives, we propose using the so-called KPSS test in which the unit root is the null hypothesis to be tested. Finally, the failure of the ADF tests to reject the unit root null hypothesis could be due to breaks or non-linearities in the trend function. The idea that a time series can be stationary around a breaking deterministic linear trend, as in Zivot and Andrews (1992) and Perron (1989), was generalized by Bierens (1997), among others, who introduced the notion of integration around a deterministic non-linear trend. As shown by Bierens (1997), considering nonlinear trends may allow rejecting the unit root hypothesis, while only correcting for trend breaks, as in Perron (1989), does not. The notion of non-linear trend stationarity can be applied to the emissions series, which are clearly non-linear. We thus focus on the Bierens (1997) revised non-linear Dickey-Fuller test, where the null of a random walk process with drift,

$$
H_{0}: z_{t}=z_{t-1}+\mu+v_{t}
$$

is tested against an alternative non-linear trend stationary process,

$$
H_{1}: z_{t}=g(t)+v_{t} .
$$

Let us denote the Chebyshev polynomial as $P_{0, n}(t), \ldots, P_{k, n}(t)$, where $P_{0, n}$ equals $1, P_{1, n}$ is a linear trend and $P_{2, n}, \ldots, P_{k, n}$ are cosine functions. Then, the ADF-type test is based on the following auxiliary regression model:

$$
\Delta z_{t}=\alpha z_{t-1}+\sum_{j=1}^{p} \phi_{j} \Delta z_{t-j}+\theta^{\prime} P_{t, n}^{m}+\varepsilon_{t},
$$

where $P_{t, n}^{m}=\left(P_{0, n}(t), \ldots, P_{m, n}(t)\right)^{\prime}$. Under the null, $\alpha=0$, and the last $m$ components of the parameter vector $\theta$ are zero. Bierens (1997) develops several test statistics. He first proposes $\widehat{t}(m)$, which is the t-statistic of the estimated coefficient $\widehat{\alpha}$, and $\widehat{A}(m)=n \widehat{\alpha} /\left|1-\sum_{j=1}^{p} \widehat{\phi}_{j}\right|$. Then, since these two tests do not account for all the available information that is incorporated in the polynomial functions $P_{t, n}^{m}$, he proposes two other tests $\widehat{F}(m)$ and $\widehat{T}(m)$ for the joint hypothesis that $\widehat{\alpha}$ and the last $m$ components of the parameter vector $\theta$ are zero. The $\widehat{F}(m)$ is a conventional Ftest, but the limiting distribution of the test under the null is not an F distribution. $\widehat{T}(m)$ is instead a $\chi^{2}$ test based on non-conventional testing principles but having a standard null distribution. The interpretation of these tests is not straightforward. The alternative hypothesis can be decomposed into two alternatives, the linear trend stationary case,

$$
H_{1}^{L}: z_{t}=\lambda_{0}+\lambda_{1} t+v_{t},
$$

and the nonlinear trend stationary case,

$$
H_{1}^{N L}: z_{t}=g(t)+v_{t}=\lambda_{0}+\lambda_{1} t+f(t)+v_{t} .
$$


Interestingly, the statistics $\widehat{t}(m)$ and $\widehat{A}(m)$ can be computed in a two-sided fashion: right-sided rejection indicates that nonlinear trend stationarity is the alternative, while left-sided rejection is not informative about the nature of the alternative, being one of mean stationarity, linear trend stationarity or nonlinear trend stationarity. The $\chi^{2}$ test should also be conducted in a two-sided way, with the rejection being informative for both sides (see Bierens, 1997, p.39-40, for a detailed discussion). Lag length selection and p-value simulation have been performed as discussed above for the standard ADF test. Concerning the Chebyshev time polynomial order $m$, ideally, it should be settled in such a way as to provide the best approximation of the non-linear trend under the alternative hypothesis. From a practical viewpoint, the choice of $m$ is difficult because if an overly low order is specified, the tests may lack power due to specification error, but conversely, if the researcher specifies an overly high order, the tests may lack power from estimating superfluous parameters. Since the exact magnitude of such opposing effects is not known, we adopt a strategy similar to Bierens (1997) by performing the test using different values for $m$, and in particular, we allow $m$ to range from 3 to 20, thus covering a wide range of different possible DGPs. The tests behave similarly for the three groups and indicate that the emission series are nonlinear trend stationary.

[table 1 here]

In summary, after taking into account i) the possible size distortion by simulating the p-values, ii) the way the test is conducted by adopting the KPSS test in which the unit root is the null hypothesis to be tested, and iii) the allowance of nonlinearities in the trend function, we can conclude that the series are stationary, and thus, we develop our analysis without using firstdifference techniques or cointegration. Table 1 summarizes the results of these tests; detailed results are available upon request.

These results seem to be particularly relevant to the EKC literature, where most of the previous studies assume that the variables are first-order integrated processes (e.g., Perman and Stern, 2003), and may suggest that further investigations addressing the low power of standard unitroot tests are needed. We argue that accommodating structural breaks and nonlinearities may have a crucial role when studying the statistical properties of $\mathrm{CO}_{2}$ emissions and GDP series for many countries (see also Heil and Selden, 1999). Further panel data studies may consider addressing such issues while also allowing for cross-sectional dependence (Lee et al., 2015; Ertur and Musolesi, 2017) because of the main role of global interdependencies and common factors driving both emissions and economic development. 


\section{Time-series methodology}

\subsection{A simple econometric model for analyzing $\mathrm{CO}_{2}$ long-run emission patterns}

We use an interrupted time series approach (Box and Tiao, 1975; Pankratz, 1991). In the spirit of Musolesi and Mazzanti (2014), it is assumed that the evolution over time of per capita $\mathrm{CO}_{2}$ emissions, taken as a proxy of GHG, can be decomposed as a function of economic development (GDP), a function of time, and an autocorrelated disturbance term:

$$
y_{t}=f\left(\mathbf{x}_{t} ; \theta\right)+g(t, \Upsilon ; \beta)+\varepsilon_{t}
$$

where $x_{t}$ is the per capita GDP (in log form), $t$ denotes time, and $f\left(\mathbf{x}_{t}, \theta\right)$ is a third-order polynomial function:

$$
f\left(\mathbf{x}_{t} ; \theta\right)=\theta_{0}+\theta_{1} x_{t}+\theta_{2} x_{t}^{2}+\theta_{3} x_{t}^{3} .
$$

The main original focus of this paper is that $g(t, \Upsilon ; \beta)$ allows for both a nonlinear (polynomial) effect of time, $\beta_{1} t+\beta_{2} t^{2}+\beta_{3} t^{3}$, and also for a finite number of interventions / unknown structural time breaks, $\Upsilon$ :

$$
g(t, \Upsilon ; \beta)=\beta_{1} t+\beta_{2} t^{2}+\beta_{3} t^{3}+\sum_{j=1}^{k} \Upsilon_{j}
$$

The error vector $\varepsilon$ is distributed as $N\left(\mathbf{0}, \sigma^{2} \Lambda\right)$, where $\Lambda$ is diagonal and $\varepsilon$ has the covariance matrix $\Lambda$. The serial error correlation is modeled using a mixed autoregressive and moving average (ARMA) process. An $\operatorname{ARMA}(\mathrm{p}, \mathrm{q})$ can be written as

$$
\varepsilon_{t}=\sum_{j=1}^{p} \rho_{j} \varepsilon_{t-j}+\sum_{l=1}^{q} \xi_{l} v_{t-l}+v_{i t}
$$

where $\rho s$ and $\xi s$ are the autoregressive and moving average parameters, respectively, and $v_{i t}$ is random Gaussian white noise. The main idea behind this simple specification is that $\mathrm{CO}_{2}$ emissions are not only driven by economic development, roughly measured by GDP, but are also related to many other factors. These factors - whose effect is approximated with a function of time - can be either country-specific or global factors. Global factors are also expected to have heterogeneous effects on emissions across countries. Such factors might include, for instance, aggregate technological shocks, global environmental policies such as the 92RC intended to reduce pollution, or oil price shocks that might influence emissions through their effects on production activity and green innovation. The heterogeneous effect of these factors may be the result, for instance, of the country-specific reaction to a global policy or country-specific technological constraints. We also imagine a situation in which some factors may have a smooth effect on emissions, which is modeled 
with a polynomial function of time, while some others may produce an effect that appears in the correspondence of some specific events such as the $92 \mathrm{RC}$, the oil price shocks, etc.

\subsection{Adding the 92RC intervention and other unknown structural breaks}

The 92RC is supposed to have brought about a 'gradual start, permanent duration' effect on the long-run carbon-income relation. This can be modeled by combining a step function with an exponential (or first-order) transfer function, that (eventually) allows for a non-linear effect of the intervention:

$$
\begin{aligned}
& \psi_{t}^{s}=\text { step_}_{-} 1993_{t}=\left\{\begin{array}{c}
1, \text { if } t \geq 1993 \\
0, \text { otherwise }
\end{array},\right. \\
& \Upsilon_{1}=[\omega \mathbf{B} /(1-\delta \mathbf{B})] \psi_{t}^{s}
\end{aligned}
$$

where $\mathbf{B}$ is the backward shift operator such that $\mathbf{B}^{i} y_{t}=y_{t-i}$. The magnitude of the impact that occurred after the event is given by $\omega$, and $\delta$ is the rate of decay of the variation (see Box and Tiao, 1975, p. 71-72). When $\delta<1$, the series will reach a new steady state, and the steady state gain is $\omega /(1-\delta)$, while $\delta>1$ will produce an exponential pattern decay. Finally, when $\delta=1$, the intervention becomes $\Upsilon_{1}=[\omega \mathbf{B} /(1-\mathbf{B})] \psi_{t}^{s}$, in which a step change in the input produces instead a more parsimonious ramp function in the output, thereby producing a linear and permanent effect of magnitude $\omega$. A ramp function can be alternatively expressed as

$$
\begin{aligned}
& \psi_{t}^{r}=\text { ramp_ }_{-} 1993_{t}=\left\{\begin{array}{c}
t-1992, \text { if } t \geq 1993 \\
0, \text { otherwise }
\end{array}\right. \\
& \Upsilon_{1}=\lambda \psi_{t}^{r}
\end{aligned}
$$

where $\lambda$ measures the magnitude of the change in the trend of the series.

Other unknown structural breaks, namely $\sum_{j=2}^{k} \Upsilon_{j}$, are detected based on the methods described by de Jong and Penzer (1998). This allows the detection of eventual additive outliers (AOs), level shift outliers (LSOs) or transitory change outliers (TCOs) and can be modeled, for example, by combining a step or a pulse function with alternative transfer functions (see also Box and Tiao, 1975) - all of which can contribute to the shape of a nonlinear long-run carbondevelopment relationship.

\subsection{Model selection}

We use a two-step selection procedure as follows.

Step one: selection of the income and time components $-f\left(\mathbf{x}_{t} ; \theta\right)$ and $g(t, \Upsilon$; $\beta)-$ of the model. We adopt a procedure starting from a model containing a cubic polynomial function 
of both income and time and the 92RC intervention (alternating between the ramp and the step function).We first select unknown breaks using the de Jong and Penzer (1998) approach. Specifically, the identification of these breaks is addressed as a problem of sequential variable selection, whose inclusion improves the quality of the estimated model. The selection process starts by considering breaks of the type specified above (AOs, LSOs, TCOs) for every time period and for the TCOs, also for every possible length, and assessing the statistical significance of each possible break. The most significant break, if it also satisfies a given significance level, which has been alternatively set as 0.05 or 0.1 , is included in the model. Then, the model incorporating the selected break becomes the model under the null hypothesis to be tested in the subsequent selection process incorporating a new break. This iterative process stops when no more significant breaks are found. In all these iterations, the other components of the model are fixed. The other components of the model, specifically those concerning the polynomial functions of time and income, are selected when the identification of breaks has been completed. This is done by dropping non-significant variables one-by-one, starting from the least significant one. At this stage, we use an AR(1) term as the initial proxy for the disturbance series autocorrelation pattern (see, e.g., Pankratz, 1991, p. 173-177).

Step two: selection of the serial correlation structure of the error term. We use the ACF/PACF/IACF functions and white noise diagnostics to deduce the appropriate error structure (e.g., Hamilton 1994). Because the estimated autocorrelation pattern does not generally provide a unique indication, being possibly consistent with different stochastic processes, we also use information criteria (AIC and BIC) to choose the most appropriate error process. These criteria are also used to compare the two alternative specifications for the $92 \mathrm{RC}$ intervention.

\section{Estimation results}

We find that both the 92RC and other unknown structural time breaks have a relevant impact and influence the groups in different ways (Table 2, Figure 1).

Regarding the 92RC intervention and concerning the Umbrella group and NE, we first note that, based either on AIC or on BIC, the model based on a ramp function is preferred over the one based on a step function with an exponential transfer function. For the Umbrella group, the analyses show a positive effect of the Rio Convention Ramp function $(\widehat{\lambda}=0.008)$ over a general negative linear trend. On the contrary, for NE, 92RC had a negative effect on the emissions $(\widehat{\lambda}=-0.019)$. Finally, SE did not show a specific statistically significant reaction to this temporal event for either a ramp or a step function. Also of note is that as a result of the model selection procedure outlined in the previous section, only selected variables are included in the regression function. These results indicate that different world areas heterogeneously reacted to the 92RC, which was one of the pillars of the Kyoto Protocol targets 5 years later.

We also note that cubic GDP is never significant (for a discussion, see Carson, 2010). All three areas present a monotonic carbon-income relationship that is linear for $\mathrm{NE}$ and quadratic for 
Umbrella and SE; the turning point is well above the range of observed per capita incomes. Indeed, for the Umbrella (SE), the turning point is obtained for $37235 \$(32435 \$)$, while the maximum observed value of per capita income is $22252 \$(17477 \$)$. Given the extremely important role of time breaks and factors different from income in explaining emissions dynamics, we argue that these values are not informative in forecasting the level of economic development that will be necessary to reach a turning point.

It is worth noting, however, that the only group that shows a non-monotonic $\mathrm{CO}_{2}$ evolution over time is NE (figure 1). This non-monotonic pattern does not appear as an inverted U-shaped curve. Instead, $\mathrm{CO}_{2}$ increases for some years up to the end of the seventies, and then, it decreases with an exponential decay pattern for some years until broadly reaching a plateau from the mideighties onward. According to our econometric model, this pattern is not explained by a polynomial function of income, which is the standard EKC argument. Rather, the following different effects explain the evolution of $\mathrm{CO}_{2}$. First, there is a positive and linear effect of GDP. Second, neither a linear nor a polynomial function of time explain $\mathrm{CO}_{2}$. Time instead affects $\mathrm{CO}_{2}$ with two breaks; the first one is detected using the approach outlined above. This shift occurred in 1980, just after the second oil shock ${ }^{2}$, as a non-linear LSO, and is modeled using a combination of a step function with an exponential transfer function:

$$
\begin{aligned}
& \psi_{t}^{s 80}=\text { step_ }_{1} 1980_{t}=\left\{\begin{array}{c}
1, \text { if } t \geq 1980 \\
0, \text { otherwise }
\end{array},\right. \\
& \Upsilon_{2}=\left[\omega_{80} \mathbf{B} /\left(1-\delta_{80} \mathbf{B}\right)\right] \psi_{t}^{s 80}
\end{aligned}
$$

The estimated parameters are $\widehat{\omega}_{80}=-0.091$ and $\widehat{\delta}_{80}=0.774$, representing, respectively, the magnitude of the impact and its rate of decay ${ }^{3}$. This result indicates a negative non-linear shift (see Hamilton, 2003), according to which the series reached a new steady level (conditional on all the other variables included in the model), with an estimated steady level loss equal to $\widehat{\omega}_{80} /\left(1-\widehat{\delta}_{80}\right)=-0.403$. Such a break takes the shape of an exponential decay function and fundamentally explains the decreasing part of the $\mathrm{CO}_{2}$ evolution over time occurring after the second oil shock up to the mid-eighties. Also note that this specific break, step_1980 $t$, does not appear to be significant for the other groups. Hamilton (2003) discusses the short- and longrun economic effects of oil shocks and recessions, including the role of exogenous events such as wars behind oil shocks. Oil shocks/energy supply reductions might relate to supply-driven or demand-driven Keynesian recessions. Two insights are relevant for the present paper. First, he finds evidence of non linearity, e.g., 'oil price increases are much more important than oil

\footnotetext{
${ }^{2}$ Linked to the Iranian war and related to a recession.

${ }^{3}$ The methodologically oriented message is that polynomial functions of time and GDP are not adequate to capture $\mathrm{CO}_{2}$ evolution. The specific economic messages are that the shock negatively influences the $\mathrm{CO}_{2}$ pattern, which then reaches an equilibrium level unless another shock intervenes.
} 
price decreases' (p.363). Second, whether it is true that oil shocks increase uncertainty and may affect economic activity through (green) investment postponement, they can induce technological breaks sooner or later. The velocity of a Green technological reaction, which is coherent with and mimics the dynamic efficiency of market-based environmental policies (Popp, 2002), depends on the specific economic and institutional conditions in a given country and on the proactive role of public investments, in addition to market investment reactions by firms and sectors. Finally, the second break is the one occurring in correspondence with the 92RC, affecting emissions negatively with a linear effect, which has been modeled according to equation (7). Also of note is that the series is a mid-length memory process given the $\mathrm{AR}(1)$ errors, with the estimated auto-regressive parameter being 0.55 .

This result adds further complementary insights with respect to Mazzanti and Musolesi (2014), who concluded that "country-specific time related factors weight more than income in driving the northern EU Environmental Kuznets. Overall, the countries differ more on their carbon-time relation than on the carbon-income relation which is in almost all cases monotonic positive. Once serial correlation and (heterogeneous) time effects have been accounted for, only three Scandinavian countries - Denmark, Finland and Sweden - present some threshold effect on the CO2development relation" (p.1). The present analyses present a complementary way to shed light on the specific time-related breaks. The message is that $\mathrm{CO}_{2}$ cannot be simply explained by a polynomial function of income, which is the standard EKC assumption, but is also driven by policy and market shocks that may influence countries' energy compositions and innovations depending on the structural conditions when the shocks occur.

Before and after the Kyoto and Rio Conventions, the northern EU countries behaved quite differently with respect to climate change policies. Scandinavian countries were the only ones to implement thorough ecological tax reform in the early 90s. The UK and Germany then also introduced green taxes aimed at reducing GHG and improving energy efficiency (Pearce, 2005). Ecological tax reforms (Andersen and Ekins, 2009) are currently still absent from other countries. Johnstone at al. (2010) also show that environmental policy stringency is higher in Germany, Denmark, and Sweden, with most Northern European countries having a value higher than 6 (1-7 index); Canada, Japan and the US in the middle of the table; and Greece, Spain and Italy showing indexes lower than 5, which is a region where some less developed countries stay.

Moreover, other studies (among others, Johnstone, Hascic and Popp, 2010 and Popp, 2002) have presented various pieces of evidence on the relation between environmental regulations and green innovations. It is interesting, when examining the trend of EPO patent applications in renewables, that the German leadership begins in the late 80s (a period when Germany started to strengthen its environmental policy commitment then influencing most EU Directives) and consolidates in the 90s. Within the EU, the established eco-innovation scoreboard places Italy, Spain, Greece and Portugal as moderate innovators and Germany, Sweden, Denmark, and Finland as leaders. R\&D figures also shows a strong divide between northern and southern EU countries. In a more global view, again considering climate-friendly patent trends (1978-2006) (Dechezlepretre 
et al., 2011), while Japan, Germany and the US rank first in terms of patent activity, it must be noted that the EU weights more than North America and Japan if one looks at inventions that are patented internationally.

Overall, it seems that the absolute delinking experienced by Northern EU countries is not attributable to income-related factors in the typical EKC adage, but is more the outcome of path-breaking reactions to policy shocks and other exogenous 'energy events'. These include the climate change Rio convention, the Iranian revolution and associated second oil price shock, and the recession in the early $1980 \mathrm{~s}^{4}$. Analyses confirm that different (groups of) advanced countries reacted differently to market and policy events. The more mature norther EU economies took advantage of the second oil shock to shift their energy mix and enhance energy efficiency. Some years later, those countries were more ready to exploit the environmental policy opportunity that 92RC presented, moving further towards economic and environmental win-win development patterns. Southern EU countries were still stuck in more development-oriented economic growth-biased paths at that time. The US, though adopting important regulations such as the various Clean Air Acts, historically focused its attention on pollution. McKitrick (2007) finds that "US economic growth and air pollution were decoupled after 1970. Possible explanations include regulation, oil price shocks, technology and income growth" (p.1).

In addition, the search procedure for the unknown breaks contributes to outlining the overall evolution of emissions. The most important ones, except for the above-mentioned breaks, relate to temporally specific positive effects on emissions that characterize the Umbrella group and SE: the effects are linked to the oil shocks of the 1970s, followed by negative effects on emissions in the 1980s. These breaks are either AOs or TCOs. The above-mentioned areas thus reacted to market shocks; a more intense use of coal could explain the positive effect just after oil shocks linked to recessions, which, after a while, contributed towards reducing the carbon levels of those economies in the mid-1980s. It thus appears that moderate market-led effects on GHG were occurring in OECD areas outside Northern Europe. Strong market signals provided stimuli. This empirical evidence might be worrying current policy makers, given the current relatively low price of oil and the still anarchic global-wide implementation of environmental policies. The postKyoto, post-Paris 2015 COP21 policy setting is moving towards the implementation of a set of regional emission trading systems (Borghesi et al., 2016). However, even today, countries within the Umbrella group do not take a political lead, with Europe and possibly China, Oceania and some US states acting as early movers in the Emission trading market development.

Historical events, path dependence and dynamic evolutions seem to suggest that the economic, policy and political conditions made it more feasible for Northern EU countries to start a de-

\footnotetext{
${ }^{4}$ It is true that in the early 90s, the invasion of Kuwait by Iraq and the following Gulf war caused an oil peak. Nevertheless, that peak in constant prices was much lower than the one caused by the Iran-Iraq war and Iranian revolution (that exceeded $100 \$$ per barrel in 2013 prices). It was comparable to the post first oil shock (Arab oil embargo) price of around $60 \$$. It is worth noting that in the early 70 s, before the first oil shock that opened the way to stagflation periods, the oil price was lower than $20 \$$.
} 
coupling pattern back in the 80s, generating a sort of 'competitive advantage', characterized by decreasing emissions and more intense production of green knowledge, namely Green technological inventions. Overall, what has driven a large part of the increased carbon efficiency in advanced countries is the fierce period characterized by a recession and string oil shocks. Some areas reacted promptly by reducing the emission intensity of the economy. Those areas thus started a pattern that ultimately led to more stringent policy actions. The history of economic development with respect to GHG evolution tells us that the starting point was a market shock. This touched basically all areas, with heterogeneous reactions. Stronger reactions created the basis for stronger environmental policy commitments ${ }^{5}$. This is not to say that market shocks (oil markets) always come first. The message is possibly that the system needs a shock to be put on the move. As an example, in the current situation with fairly low oil prices, a set of carbon taxes in key countries may act as a first driving force ${ }^{6}$. Currently, there is a debate around whether the ETS price is low or signals efficiency in carbon abatement (Borghesi et al., 2016). It remains unclear whether the implementation of ETS systems alone will be sufficient to achieve the pretty radical abatements ( $-90 \%$ by 2050 with respect to 1990 on average) economies demand to stabilize emissions and temperatures (Ekins and McGlade, 2015).

Then, there are differences across countries within the three groups as well. We convey some country-based analyses, and Table 3 presents a summary of the $92 \mathrm{RC}$ effects.

[table 2 here]

[figure 1 here]

The country-specific results show that overall, the $92 \mathrm{RC}$ effect is coherent with the group aggregate effect, but some countries show specific effects. SE does present some country-based positive effects, contrary to the aggregate non-significant effect. Within NE, the following three countries show significant negative effects in terms of emissions: Finland, Netherlands and Germany. The latter two are countries with historical commitment to environmental policy and high exposure to international markets through trade relationships Finally, among the Umbrella group, it is worth noting that although Norway has largely being detached from the EU approach to climate policies, it seems to be aligned with the NE trends of a negative 92RC effect on emissions. Indeed, its economic and policy connections with the UK and Scandinavia were and are strong. Overall, only four countries show a negative 92RC effect, which shows the possible relevance of policy events, on the one hand, and the difficult challenge of reverting GHG trends, on the other, which we still witness.

[table 3 here]

\footnotetext{
${ }^{5}$ This highlights that assumed and unknown time-related events dynamically explain the overall EKC shape and are interrelated in certain circumstances (NE).

${ }^{6} \mathrm{~A}$ 'shock' might be a sudden unexpected jump in a variable (covariate) or a credible policy that develops from a given time $\mathrm{T}$ onwards. The second case is historically rare but possible.
} 


\section{Conclusions}

This paper sheds light on the structural breaks that may have affected the long-run carbon evolution. By using an interrupted time series approach, the paper captures the relevance of market- and policy-related time events, thus complementing some recent works that have used panel datasets to analyze the role of income and time effects. The analyses highlight two main messages. First, historical carbon dynamics are affected by structural breaks in some countries. This evidence further supports the fallacy of a simplistic environmental Kuznets-like argument. Emissions trends seem to be the result of a series of heterogeneous reactions to market and policy shocks, which ultimately determine complex nonlinear paths. Although per capita income levels may be comparable, different innovation and policy responses and dynamics can lead to quite different emissions performance. Thus, the way income influences environmental quality cannot be expected to be a time-unrelated relationship. Second, these paths seem to be categorized into three 'development models' for high income countries. A 'market-led' model characterized the Umbrella group, whose GHG emission pattern is mainly explained by reactions to market (oil) shocks. A 'market- and policy-led model' instead characterized Northern Europe, which promptly reduced emissions after the second oil shock and afterwards presented a negative effect in terms of emissions driven by policy stimuli that occured back in the early 1990s. Southern Europe followed a more standard 'development-driven' model, where both income and time appear to have a nonlinear effect on the emissions.

The main message of this study is that carbon dynamics are largely explained by time-related breaks. The Northern EU countries seem to have taken earlier actions to achieve climate-oriented economic restructuring by reacting both to market and policy events in a consequential and complementary manner. In contrast, whereas the Umbrella group reacted with some delay to oil shocks through enhanced carbon efficiency, NE promptly reacted to the second oil shock and subsequently to the 1992 Rio convention, ultimately becoming a leading actor in the climate change policy agenda. An important factor that remains to be investigated is the extent to which a fraction of GHG emissions has been delocalized to emerging and developing countries, now appearing in the import-embodied emissions. This means that both Consumption- and Production- related emissions (Sustainable Consumption and Production) should be assessed to evaluate a country's performance as its trade relationships intensify (EEA, 2014).

Understanding whether international environmental agreements and other specific exogenous shocks affected emissions is relevant for future climate negotiations. Interestingly, our results partially contradict Almer and Winkler (2017) who find that the Kyoto protocol had no effect on emission trends for Annex-B countries. While we exploit the time series dimension, they adopt a synthetic control method, i.e. a purely treatment effect approach. We argue that future research is needed in the area. Further methodological improvements within the framework of time series analysis, could be achieved by estimating and testing structural breaks within the more general framework of nonparametric regression (see, e.g. Delgado and Idalgo, 2000; Su and Xiao, 2008). 


\section{References}

[1] Almer C. Winkler R. (2017), Analyzing the effectiveness of international environmental policies: the case of the Kyoto Protocol, Journal of Environmental Economics and Managment, 82, 125-151.

[2] Andersen M.S., Ekins P. (2009), Carbon Taxation: Lessons from Europe, Oxford University press, Oxford/NY.

[3] Barrett S. (2003) Environment and Statecraft, Oxford University Press.

[4] Bierens, H. J. (1997) Testing the unit root with drift hypothesis against nonlinear trend stationarity, with an application to the US price level and interest rate, Journal of Econometrics, $81,29-64$.

[5] Borghesi, S., et al. (2016) The European Emission Trading System and Its Followers: Comparative Analysis and Linking Perspectives. Springer, 2016.

[6] Box G.E.P., Tiao G.C. (1975) Intervention analysis with applications to economic and environmental problems, Journal of the American Statistical Association, 70, 70-92.

[7] Brock W., Taylor S. (2010) The Green Solow Model, Journal of Economic Growth, 15, 127-53

[8] Carson R.T. (2010) The Environmental Kuznets curves: seeking empirical regularity and theoretical structure, Review of environmental Economics and Policy, 4,1, 3-23

[9] de Jong, P. Penzer, J. (1998) Diagnosing Shocks in Time Series, Journal of the American Statistical Association, 93, 442.

[10] Dechezlepretre A., Glachant M., Hascic I., Johnstone N., Meniere N. (2011), Invention and transfer of climate change mitigation technologies on a global scale: a study drawing on patent data, The Review of Environmental Economics and Policy, January (previous version FEEM working paper 82, FEEM, Milan).7

[11] Delgado, M. A., \& Hidalgo, J. (2000). Nonparametric inference on structural breaks. Journal of Econometrics, 96(1), 113-144.

[12] Dickey, D. A. Fuller, W.A. (1979) Distribution of the Estimators for Autoregressive Time Series With a Unit Root," Journal of the American Statistical Association, 74 (366), 427-431.

[13] Ekins, P., Speck, S., (2011), Environmental Tax Reform (ETR). A Policy for Green Growth, Oxford University Press

[14] European Environment Agency. The European Environment —. Environmental Taxation and EU Environmental Policies. European Environment Agency, 2016. 
[15] —. Resource Efficient Green Economy and EU Policies. European Environment Agency, 2014.

[16] Ertur, C., \& Musolesi, A. (2017). Weak and Strong Cross-Sectional Dependence: A Panel Data Analysis of International Technology Diffusion, Journal of Applied Econometrics, 32, p. 477-503.

[17] Grossman G.M., Krueger A.B. (1995) Economic Growth and the Environment, Quarterly Journal of Economics, May, 353-357.

[18] Johnstone N., Hascic I., Kalamova M. (2010), Environmental Policy design characteristics and technological innovation, OECD environment working paper 15, OECD Paris.

[19] Johnstone N., Hascic I., Popp, D. (2010), Renewable energy policies and technological innovation: evidence based on patent counts, Environmental \& Resource Economics, 45, 133-55.

[20] Kwiatkowski, D, Phillips, P. C. B., Schmidt, P. and Shin, Y. (1992) Testing the null hypothesis of stationarity against the alternative of a unit root: how sure are we that economic time series have a unit root?, Journal of Econometrics, 54, 159-78.

[21] Hamilton, J. D. (1994) Time Series Analysis. Princeton: Princeton University Press.

[22] Hamilton, J. D. (2003). What is an oil shock?. Journal of econometrics, 113(2), 363-398.

[23] Harbaugh, W. T., Levinson, A., Wilson, D. M. (2002) Reexamining the empirical evidence for an environmental Kuznets curve. Review of Economics and Statistics 84, 3, 541-551.

[24] Härdle, W., \& Mammen, E. (1991). Bootstrap methods in nonparametric regression. In Nonparametric Functional Estimation and Related Topics (pp. 111-123). Springer Netherlands.

[25] Heil M.T. and Selden T.M., (1999), Panel stationarity with structural breaks: carbon emissions and GDP, Applied Economics Letters, 6:4, 223-225.

[26] Lee, C., Wu, J. L., \& Yang, L. (2015). A Simple Panel Unit-Root Test with Smooth Breaks in the Presence of a Multifactor Error Structure. Oxford Bulletin of Economics and Statistics.

[27] Mazzanti M., Musolesi A. (2013) The heterogeneity of carbon Kuznets curves for advanced countries: comparing homogeneous, heterogeneous and shrinkage/Bayesian estimators, Applied Economics, 45, 3827-42.

[28] Mazzanti, M., Musolesi, A., (2014) Nonlinearity, heterogeneity and unobserved effects in the carbon dioxide emissions-economic development relation for advanced countries, Studies in Nonlinear Dynamics \& Economics, 18, 521-541.

[29] McGlade, C., Ekins, P. (2015), "The geographical distribution of fossil fuels unused when limiting global warming to $2{ }^{\circ} \mathrm{C}$ ". Nature $517,187-190$ 
[30] McKitrick R. (2007), Why did US air pollution decline after 1970? Empirical Economics, , Volume 33, Issue 3, pp 491-513

[31] Panopolou E. Pantelidis T. (2009), Club convergence in carbon dioxide emissions, Environmental and Resource Economics, vol. 44, pp. 47-70.

[32] Pankratz, A. (1991) Forecasting with Dynamic Regression Models, New York: John Wiley \& Sons, Inc.

[33] Pearce D.W. (2005), The political economy of an energy tax: The United Kingdom's Climate Change Levy, Energy Economics, vol.28, 2, 149-58.

[34] Perman, R., and Stern, D.I., (2003), Evidence from panel unit root and cointegration tests that the environmental Kuznets curve does not exist. Australian Journal of Agricultural and Resource Economics, 47(3), 325-347.

[35] Perron, P. (1989) The great crash, the oil price shock, and the unit root hypothesis, Econometrica, 57, 1361-401.

[36] Perron, P. (2006). Dealing with structural breaks. Palgrave handbook of econometrics, 1(2), 278-352.

[37] Popp, D. (2002), Induced Innovation and Energy Prices, American Economic Review, 92, 160-180.

[38] Su, L., \& Xiao, Z. (2008). Testing structural change in time-series nonparametric regression models. Statistics and its Interface, 1(2), 347-366.

[39] Zivot, E. and Andrews, D. (1992) Further evidence of the great crash, the oil-price shock and the unit-root hypothesis, Journal of Business and Economic Statistics, 10, 251-70. 


\begin{tabular}{|c|c|c|c|}
\hline Method & Umbrella & Southern Europe & Northern Europe \\
\hline $\mathrm{ADF}$ & Random Walk & Random Walk & Random Walk \\
\hline Simulated ADF & Trend Stationarity & Trend Stationarity & Trend Stationarity \\
\hline KPSS & Trend Stationarity & Trend Stationarity & Trend Stationarity \\
\hline BIERENS & Nonlinear Trend Stationarity & Nonlinear Trend Stationarity & Nonlinear Trend Stationarity \\
\hline \multicolumn{4}{|l|}{ Notes. } \\
\hline
\end{tabular}




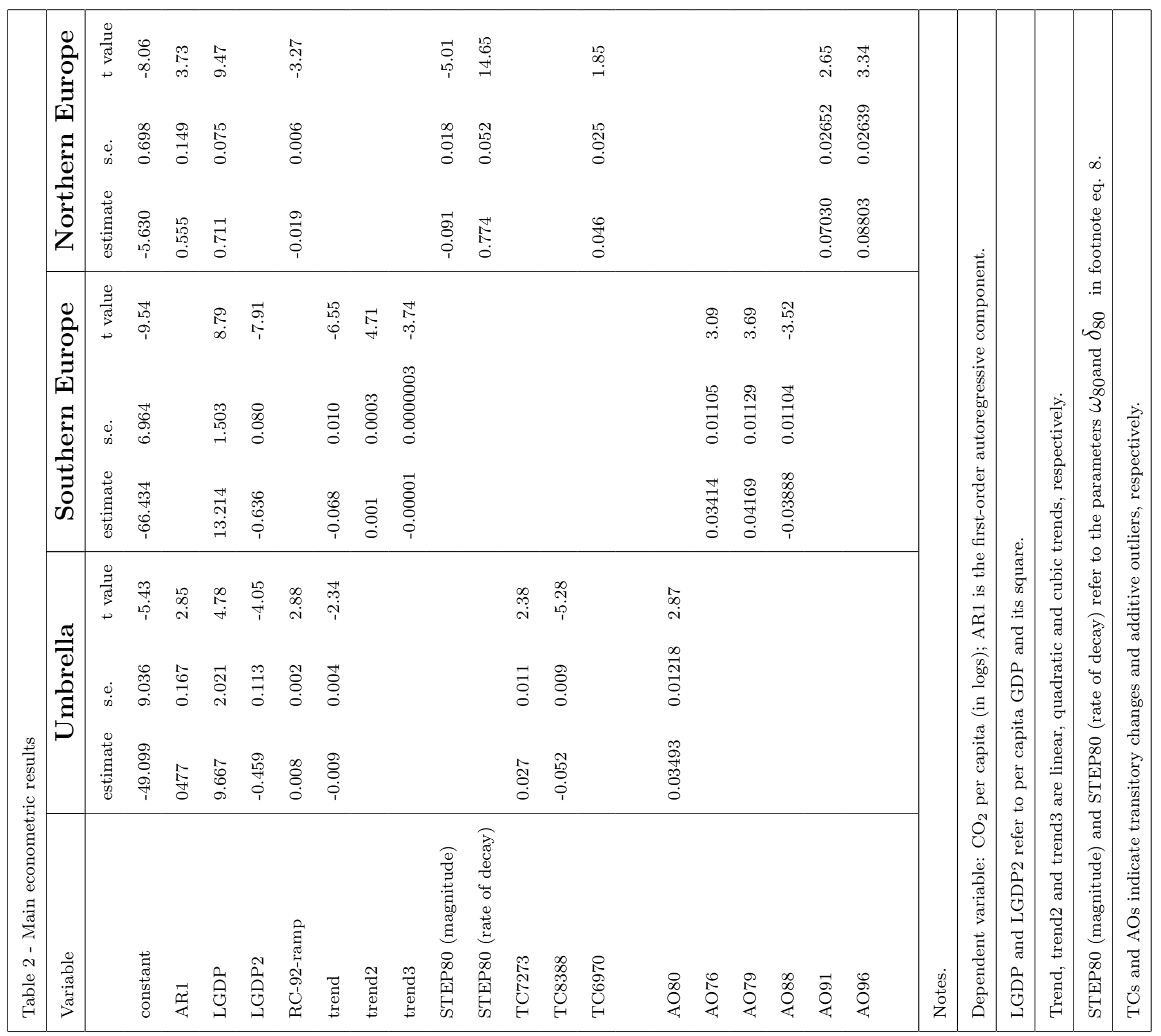




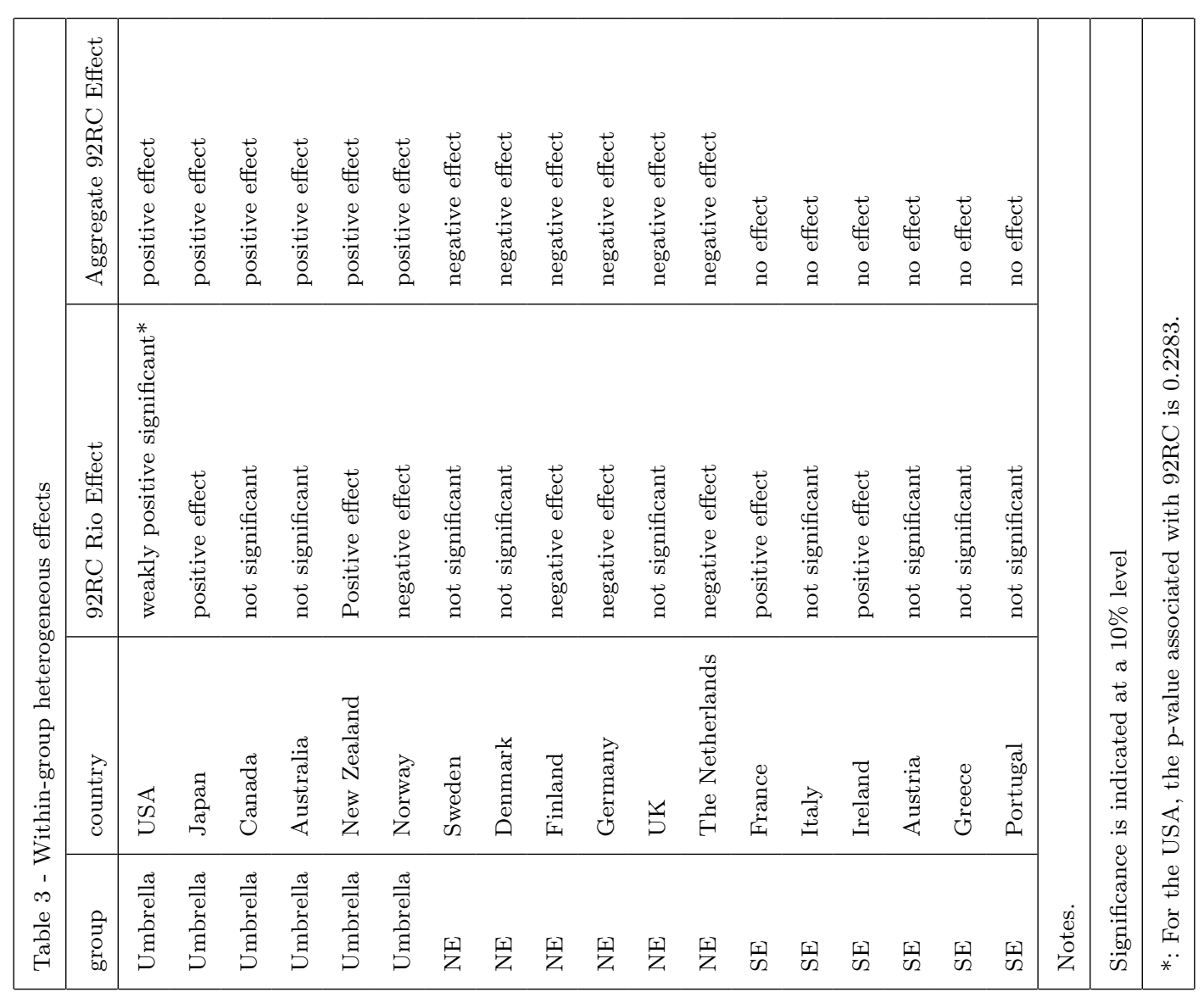




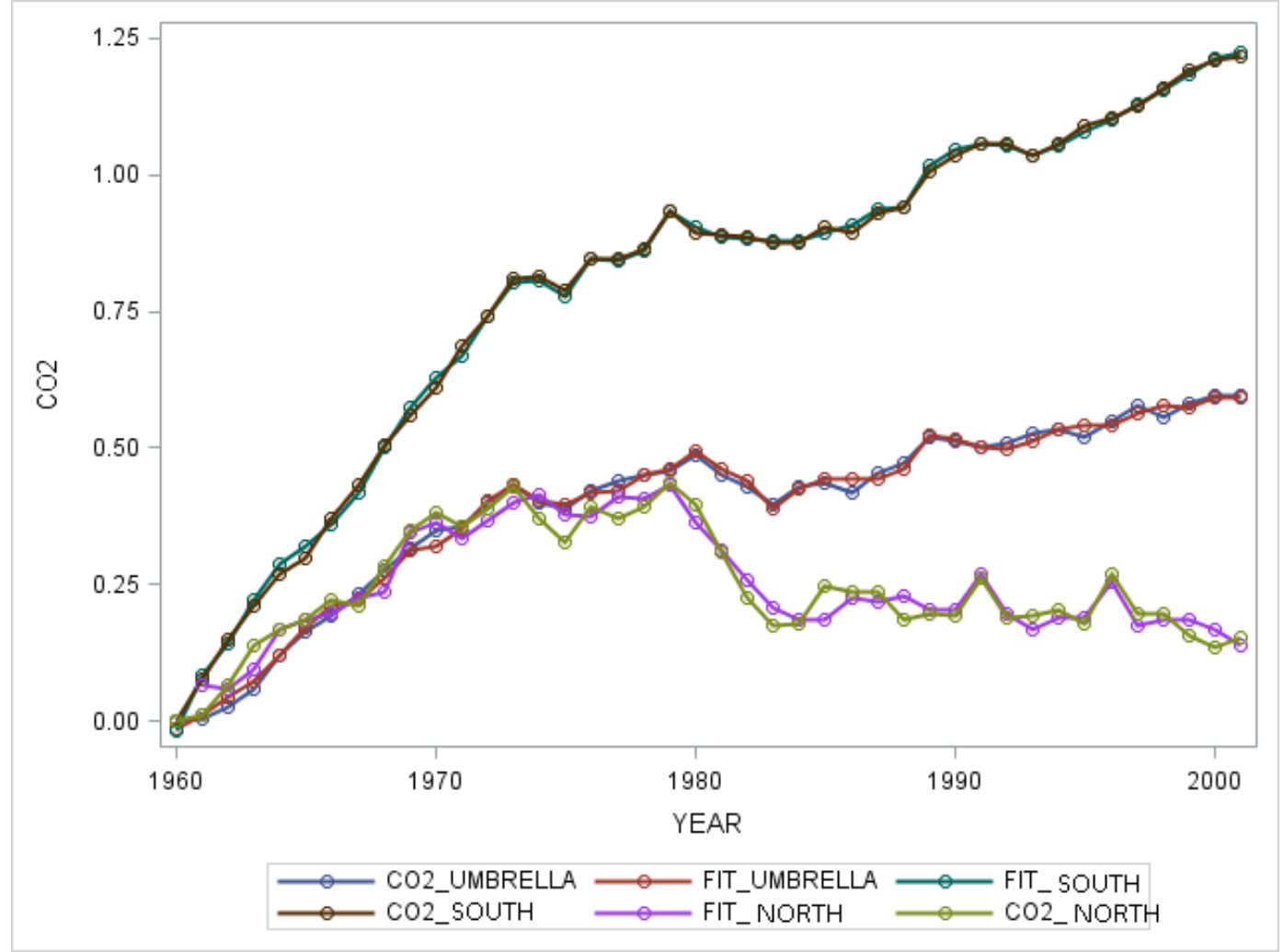

Figure 1: Real and fitted values 